\title{
The Renewable Energy Revolution of Reunion Island
}

\author{
Sandrine SELOSSE ${ }^{a_{1}}$, Sabine GARABEDIAN ${ }^{\mathrm{b}}$, Olivia RICCI $^{\mathrm{b}}$, Nadia MAIZI ${ }^{\mathrm{a}}$ \\ a MINES ParisTech, PSL Research University, CMA - Centre for Applied Mathematics, Rue Claude \\ Daunesse, 06904 Sophia Antipolis, France \\ ${ }^{\text {b } U n i v e r s i t e ́ ~ d e ~ l a ~ R e ́ u n i o n ~-~ C E M O I, ~} 15$ avenue René Cassin, BP 7151, 97715 St-Denis, La Réunion
}

\begin{abstract}
Reunion Island, a French overseas region located in the Indian Ocean, is facing a three-fold challenge combining demographics, the environment and energy. To limit its heavy dependence on imported fossil fuels, Reunion Island aims to achieve energy autonomy by 2030 based on greater energy efficiency and renewable energy alternatives. The objective of this study is to analyze different scenarios to reach electricity autonomy and, at the same time, consider the wide-scale integration of renewable energy in the island's power system using the bottom-up optimization energy model TIMES-Reunion. Despite the tremendous potential of renewable energy sources present on the island, the transition to $100 \%$ renewable energy needs to be supported by incentives or constraints. Strong energy policies can both direct the choice of renewable resources and accelerate the renewable transition. The development of biomass on Reunion Island is economically interesting. The transition scenarios show that by 2030, electricity from biomass advantageously replaces electricity from coal and represents slightly more than $50 \%$ of electricity generation. Solar and wave/ocean energies are not the most cost effective option, but wind energy tends to disappear in the face of these energies more politically supported. A network regulation rule benefits biomass and is more detrimental to solar than to wave energy. The decarbonized transition of the power system incurs higher total discounted system costs due to the additional costs induced by the different incentives to promote certain renewables, with some pathways toward energy autonomy appearing more costly than others.
\end{abstract}

Keywords: Reunion Island; Energy System; Energy autonomy; Renewables; Long-term modeling

\section{Highlights}

- Reunion Island aims to achieve energy autonomy and a $100 \%$ renewable electricity mix by 2030

- Without policy support, the share of renewables remains at the 2008 reference level

- The development of biomass, particularly energy cane, is economically interesting.

- Solar and marine energy need political and/or economic support to be developed

\footnotetext{
${ }^{1}$ Corresponding author: sandrine.selosse@mines-paristech.fr
} 


\section{Introduction}

Declared a UNESCO world heritage site in 2010, the French overseas region of La Reunion - Reunion Island - located between Mauritius and Madagascar in the Indian Ocean, is facing a three-fold challenge involving demographics, the environment and energy. From 1970 to 2012, the island's population nearly doubled from 450,000 to 837,900 inhabitants. According to INSEE 2012 projections [1], the number of inhabitants is expected to reach 1,061 million in 2040. In a context of demographic and economic growth, between 2000 and 2012, primary energy consumption increased by 3.1\% per year and final energy consumption by $2.5 \%$ per year. Whereas in the 1980s all of the energy produced on Reunion Island came from renewable hydroelectricity, the island has gradually become dependent on imported fossil fuels. In 2015, petrol, coal and gas represented $86.1 \%$ of primary energy consumption and renewable energies only $13.9 \%$, while $64 \%$ of the island's power was generated by fossil fuel (coal and oil) power plants [2]. This strong dependence on imported fossil fuels is frequently observed in the island's energy system [3] and leads to power outage risks in case of supply disruption as well as increasing greenhouse gas emissions. Most of the world's islands are in a similar situation and have to import fossil fuel for their energy demands, which is increasingly expensive for island nations [4][5][6][7]. Yet, although Reunion Island is isolated, located far from mainland France, and equipped with a poorly meshed grid that makes it vulnerable, it does possess significant potential in terms of renewables, such as hydropower, solar, wind, biomass, geothermal energy and marine energy in the form of ocean thermal energy and energy waves [8]. As for some other islands, renewable energy sources are thus sufficiently abundant to explore opportunities for an autonomous, sustainable power system [9][10].

Like other French overseas territories, Reunion Island has been significantly investing in renewable energy since 2000 [8] and, notably, since 2007 it has adopted a strategy for sustainable development that aims to achieve energy autonomy by 2030 based on greater energy efficiency and renewable energy alternatives [11] [12] [13]. Although half of the island's power is currently generated by coal-fired power plants, this unique European territory in the Indian Ocean has considerable potential for renewable energy generation (solar, marine, wind and biomass), and so is largely targeting developing these renewable energy sources to achieve its goal. Until recently, Reunion Island had implemented the GERRI project [14], Green Energy Revolution Reunion Island. This economic and social development program centered on the sustainable development of Reunion Island and resulted from the "Grenelle Environment" French environment roundtables. It established an energy self-sufficiency target for Reunion Island by 2030, by replacing fossil fuels with renewable sources. This project aimed to build a model of production and energy consumption by 2030 promoting all low-carbon innovations for integration into society by 2030; this included transport, energy production, storage and use, town planning and construction, and also tourism, with La Reunion aiming to develop an ecological tourism sector receiving 600,000 tourists by 2020. Reunion Island's plan for making its electricity system $100 \%$ renewable involved a multi-fold process. This ambition was established in the law "Grenelle 1" No. 2009-967, whereby the French Ministry of Ecology mandated in April 2009 that all new constructions in overseas departments must install solar water heating. Additionally, biomass was to gradually substitute coal, entailing the development of more fibrous sources of sugarcane, and thus an increase in the number of cane farms It was established that more hydropower and geothermal energy should enter the mix, accompanied by experiments on tidal power. These measures were also designed to help the island achieve its goal of satisfying all of its heating and cooling needs with renewable resources. The GERRI project was dissolved 
in 2013, but energy autonomy remains a challenge and a goal to reach, enshrined by the Energy Transition for Green Growth Act launched in France in 2015.

Achieving energy autonomy by 2030 will require a $100 \%$ renewable electricity mix by this date. Owing to its rich natural environment, this unique European territory in the Indian Ocean has exceptional potential for renewable power generation. Reunion Island is endowed with many types of renewable energy sources (RES) such as solar, wind, geothermal, sea energy (ocean thermal energy conversion and wave energy), biomass and hydropower. However, reaching this 100\% renewable electricity mix will involve many structural changes in electricity production in a short time-frame. Hydroelectricity is the island's main renewable resource. It accounted for 17,2\% of its total electricity production in 2015 (133,6 MW of installed capacity), spread over six sites in the eastern part of the island [2]. An additional capacity of 50 MW should be deployed by 2030 [15]. Reunion Island's biomass potential is considerable. The bagasse (sugar cane residue) resulting from the sugar cane industry is entirely energy-valued in two co-firing bagasse and coal power plants. Biomass will have to be largely deployed to substitute coal in the long term, which will entail the development of more fibrous sources of sugarcane, the reclamation of wood and green waste energy and the development of gasification technologies. Due to the island's location, solar energy is an abundant energy resource. Over the last ten years, a large increase of photovoltaic (PV) installations has been observed. The first PV systems set up were stand-alone systems specially in isolated mountain places that couldn't be easily connected to the grid. Nowadays, PV farms connected to the grid are developed mainly on the coastal part of the island due to its high solar potential. the PV farms are mainly set up on residential houses and industrial roofs due to landscape constraints. In 2015, the installed capacity of photovoltaic solar energy was 186,6 MW [2]. To meet the autonomy target, more PV farms connected to the grid will have to be developed [8].

The southeast and northeast regions of the island are suitable for wind power generation [8]. Currently, two wind farms are operating with a total installed capacity of 14,8 MW in 2015 [2]. The potential of wind power generation is estimated at $50 \mathrm{MW}$ for the island. During the summer season the island is exposed to violent cyclones. Therefore, special wind turbines insured for cyclonic conditions (pull-down wind turbine technology) have been developed in the two farms. The investment extra cost and the non-exploitation during cyclonic winds thus limit the investment in wind power on the island despite an important potential on the coast [2] [8]. Furthermore, several other renewable technologies will have to enter the mix, such as geothermal and marine energies. Research projects on marine energies are under development [8]. Ocean thermal energy conversion (OTEC) will have to be largely deployed as well as wave energy. Geothermal energy also has significant potential thanks to a high thermal gradient with the Piton de la Fournaise volcano. However, this potential is still under study as the volcano is located in a protected natural zone.

The high penetration of RES in the power mix raises key issues: What will be the cost of electricity autonomy by 2030? How will the significant deployment of intermittent energies affect the reliability of the electrical system? A quantification of these issues is useful to define a road map to meet the goal of electricity self-sufficiency. To address these issues, we have conducted a prospective analysis of the Reunion Island electricity system by 2030. The objective is to examine the changes in current production patterns in order to move toward a $100 \%$ renewable mix by 2030 . The aim of this study is to evaluate the impact of differentiated large-scale integration of renewable energy on the composition of the electricity mix, the total additional cost to the system induced by this $100 \%$ renewable objective, and the effect of a limitation of intermittent penetration due to network reliability consideration. This analysis is conducted 
with the bottom-up energy model TIMES-Reunion [16] [17][18]. The paper is organized as follows: section 2 describes the model used for the analysis and the energy scenarios. Section 3 presents the results of the long-term modeling. The final section provides some concluding remarks.

\section{Methodology and energy autonomy scenarios}

\subsection{The TIMES-Reunion model}

This analysis was developed with the TIMES-Reunion model developed by the MINES ParisTech Centre for Applied Mathematics [16]. The TIMES model is a widely used, linear programming family model developed under the IEA's Energy Technology Systems Analysis Program (ETSAP). It is a bottom-up optimization model that offers a technology-rich representation of Reunion Island's electricity system [19][20][21], which it depicts with a detailed description of different primary energy sources, electricity production, transport and distribution technologies constituting the reference electricity system (figure 1). The RES network links these commodities to numerous technologies characterized by their economic and technological parameters in the power sector.

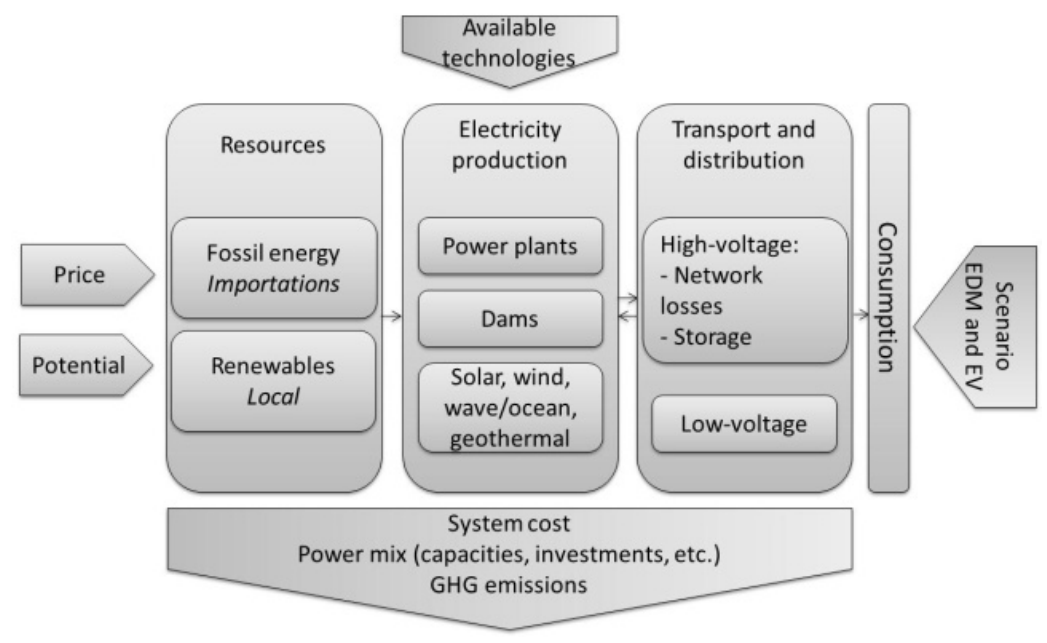

Figure 1: Reunion Island Reference Energy System

The time horizon of the model ranges from 2008 (reference year) to 2030. This technological model is driven by an exogenous electricity demand. The model uses a linear-programming approach in which the technical optimum is computed by minimizing the discounted global system cost. Then, the model aims to supply energy services at minimum global cost by simultaneously making decisions on equipment investment and operation, and primary energy supply. It minimizes the total discounted cost of the Reunion's electric system over a long time period under a number of environmental, technical and demand constraints. It computes a total net present value of the stream of the total annual cost, discounted at $7 \%$ to the selected reference year 2008. The total annual cost includes investment and dismantling costs (capital costs) that are annualized using hurdle rates, annual fixed and variable operation and maintenance costs, and costs incurred for exogenous imports and domestic resource production. The main outputs of the model are future investments and activities of technologies for each time period. Furthermore, the structure of the energy system is given as an output, i.e. type and capacity of the energy technologies, energy consumption by fuel, emissions, etc. 
The model is calibrated for the reference year, 2008 when 9,165.6 TJ of electricity was generated [22]. Costs and technical properties for new power plants are derived from the European program RES2020, which assessed the directives on Renewable Energy Sources in the European Union using a TIMES model. Figure 2 shows the Reunion Island electricity mix in 2008, a mix dominated by fossil fuels, although hydroelectricity and biomass with sugarcane are well represented. Indeed, $64 \%$ of electricity production was supplied by fossil primary energy comprising some oil but mostly coal, and 36\% by renewables. Hydroelectricity represented close to $25 \%$ of the power generation and $69 \%$ of renewable electricity. The significant amount of sugarcane crops means that bagasse (residue of sugarcane) could be used in electricity production. Bagasse was thus used as a fuel in two thermal power plants, in co-firing with coal. 550,000 tons of bagasse were produced and recovered in these two plants per year, so that this resource represented $10 \%$ of electricity generation sources. In 2008, solar and wind energies were insignificant sources of electricity generation.

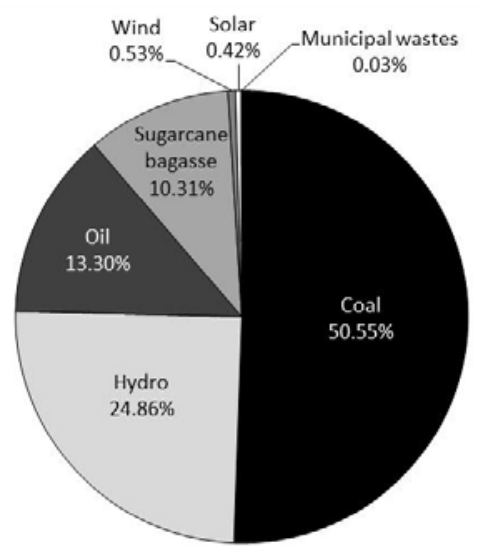

Figure 2: Electricity production in 2008 (source: PPI - EDF SEI 2009) [2]

$76 \%$ of the installed capacities in 2008 concern thermal power plants, representing 476 MW. Hydropower represents $20 \%$ of the installed capacities distributed between dams for $109.4 \mathrm{MW}$ and run of river for 11.6 MW. The remainder of the installed capacities is constituted by wind power, representing 16.8 MW, solar power, representing $10 \mathrm{MW}$, and municipal waste, with $2 \mathrm{MW}$.

Reunion Island is electrically isolated and so has to produce the energy it consumes. Considering its power mix, Reunion Island is significantly dependent on fossil energies. Given the island's energy autonomy ambition, the potentials of renewable energies by 2030 (table 1) are based on policies and projects conducted in Reunion Island, and mainly on the SRCAER (2013) [15].

Table 1: Renewable energy potential assumptions

\begin{tabular}{ccc} 
Energy sources & Level in 2008 & Potential \\
\hline Biomass & $963 \mathrm{TJ}$ & $1,440 \mathrm{TJ}$ \\
\hline Hydroelectricity & $121 \mathrm{GW}$ & $268 \mathrm{MW}$ \\
\hline Wind & $16.8 \mathrm{MW}$ & $50 \mathrm{MW}$ \\
\hline Solar PV & $10 \mathrm{MW}$ & $160 \mathrm{MW}$ \\
\hline Ocean thermal energy conversion (OTEC) & & $10 \mathrm{MW}$ in 2020 \\
\hline Ocean wave & $100 \mathrm{MW}$ in 2030 \\
\hline Geothermal & $30 \mathrm{MW}$ by 2020 \\
\hline
\end{tabular}


Renewable energies are expected to significantly increase by the 2030 time horizon. Notably, intermittent energy presents considerable potential for development. From 1.68 MW and 10 MW respectively, the installed capacity of wind and solar could increase to reach $50 \mathrm{MW}$ and $160 \mathrm{MW}$ respectively on the time horizon. In addition, the development of the use of bagasse and marine energy should significantly contribute to achieving electricity autonomy on Reunion Island. The potentials of these renewables are substantial with, for example, up to $100 \mathrm{MW}$ of installed capacity of ocean thermal energy in 2030, and 1,440 TJ of biomass electricity generation. Geothermal energy also presents significant potential for development, with an installed capacity of $30 \mathrm{MW}$; however, the main problem for this resource on Reunion Island is its location in a protected natural area.

To analyze possible alternative development pathways of the future autonomous energy system, we investigate different scenarios binding the target of 100\% renewable sources in power generation by 2030 and specifying different potentials for renewable energy sources. Moreover, we implement a sensitivity analysis with a particular focus on solar, ocean energy, geothermal and sugarcane.

\subsection{Scenarios}

We start by calculating a business as usual scenario. In this reference scenario, no specific energy policy is assumed. There is no objective to integrate renewable energy into the mix to reach electricity selfsufficiency. This scenario outlines some key patterns in the evolution of the electricity system and serves as a comparison point of the analysis.

To achieve the electricity autonomy objective and meet the $100 \%$ renewable target, we analyze the "100\% Renewable" scenario. In this scenario, fossil fuel is no longer present in the electricity mix by 2030. Additionally, $300 \mathrm{MW}$ of solar has to be installed by 2020. This scenario allows us to investigate the pathway induced by a strong energy policy.

We also explore the impact on the system of strong political choices. Since 2000, public policies have largely incentivized photovoltaic solar energy and the development of marine energies. Therefore, we consider a specific $100 \%$ renewable scenario where photovoltaic and ocean energy systems are significantly developed to meet the $100 \%$ renewable target, " $P V-O C E$ scenario", i.e. $700 \mathrm{MW}$ for solar and $150 \mathrm{MW}$ for ocean energy.

Another scenario consists in achieving the 100\% renewable target with large-scale deployment of geothermal energy and biomass. Geothermal is developed through authorizing the exploitation of geothermal energy in a protected natural area. The sugarcane resource produced on the island is only devoted to energy. This scenario is called "Rupture".

Then, in relation to the potentially large-scale development of intermittent energy, we investigate scenarios dealing with the management of this intermittency, including an exploitation rule in line with the decision of the network operator EDF (Electricity of France) that consists in limiting intermittent energy in the grid to a maximum of $30 \%$. This limitation concerns more precisely solar, wind, wave energy, and run of river. The aim of this constraint is to take into account power network reliability concerns. These scenarios are called "PV-OCE Int" and " $100 \%$ Ren-Int". Renewable energy potentials are similar to those in scenario $P V-O C E$ and $100 \%$ renewable only the share of intermittent energy sources in the power mix is limited to $30 \%$. 
The demand for electricity in the model is exogenous, and data come from the projections of the network operator EDF. In the different scenarios, we assume that energy demand management will be put in place. Therefore, the increase in demand is lower than in a $B A U$ and we expect the deployment of electric cars by 2030 (Table 2).

Table 2: Electricity demand scenarios

\begin{tabular}{lcccccc} 
Demand scenario & $\mathbf{2 0 0 8}$ & $\mathbf{2 0 1 0}$ & $\mathbf{2 0 1 5}$ & $\mathbf{2 0 2 0}$ & $\mathbf{2 0 2 5}$ & $\mathbf{2 0 3 0}$ \\
\hline Median & & & & & & \\
Electricity demand (TJ) & $8,344.8$ & $8,881.2$ & $10,191.6$ & $11,473.2$ & $12,470.4$ & $13,435.2$ \\
\hline $\begin{array}{l}\text { Energy demand control } \\
\text { Electricity demand (TJ) }\end{array}$ & $8,344.8$ & $8,866.8$ & 9,900 & 10,260 & $10,486.8$ & $10,645.2$ \\
\hline $\begin{array}{l}\text { Electric cars } \\
\text { Electricity demand (TJ) }\end{array}$ & & & & 0 & & 5,040 \\
\hline
\end{tabular}

Furthermore, in case of energy demand management (EDM), the grid's power peak is also expected to go down (Table 3).

Table 3: Grid power peak scenarios

\begin{tabular}{lcccccc} 
EDM scenario & $\mathbf{2 0 0 8}$ & $\mathbf{2 0 1 0}$ & $\mathbf{2 0 1 5}$ & $\mathbf{2 0 2 0}$ & $\mathbf{2 0 2 5}$ & $\mathbf{2 0 3 0}$ \\
\hline $\begin{array}{l}\text { Median } \\
\text { Power peak (MW) }\end{array}$ & 408 & 445 & 520 & 595 & 670 & 750 \\
$\begin{array}{l}\text { Energy demand control } \\
\text { Power peak (MW) }\end{array}$ & 408 & 435 & 480 & 521 & 560 & 596 \\
\hline
\end{tabular}

The following table summarizes the scenarios:

Table 4: Scenario characterization

\begin{tabular}{|c|c|c|c|c|c|}
\hline $\begin{array}{c}\text { Scenarios } \\
\text { Specificities }\end{array}$ & $\begin{array}{c}100 \% \\
\text { Renewable }\end{array}$ & PV-OCE & Rupture & $\begin{array}{c}\text { 100\% Ren- } \\
\text { Int }\end{array}$ & PV-OCE-Int \\
\hline $\begin{array}{c}2030 \text { energy } \\
\text { goal }\end{array}$ & \multicolumn{4}{|c|}{ No more fossil fuel by 2030 - ELECTRICITY AUTONOMY } \\
\hline $\begin{array}{c}\text { Energy } \\
\text { policy }\end{array}$ & $\begin{array}{c}300 \mathrm{MW} \text { solar } \\
\text { by } 2020\end{array}$ & $\begin{array}{c}\text { PV and ocean } \\
\text { energy system } \\
\text { significantly } \\
\text { developed }\end{array}$ & $\begin{array}{c}\text { Geothermal } \\
\text { energy and } \\
\text { biomass }\end{array}$ & $\begin{array}{c}300 \mathrm{MW} \\
\text { solar by } 2020\end{array}$ & $\begin{array}{c}\text { PV and ocean } \\
\text { energy system } \\
\text { significantly } \\
\text { developed }\end{array}$ \\
\hline $\begin{array}{c}\text { Exogenous } \\
\text { demand } \\
\text { evolution }\end{array}$ & Scenario Energy Demand Control (EDC) and Electric Cars (EC) \\
\hline $\begin{array}{c}\text { Network } \\
\text { exploitation } \\
\text { rule }\end{array}$ & No limitation of intermittent energy & $30 \%$ maximum of intermittent \\
\hline
\end{tabular}

\section{Results}

We analyze the changes in current electricity production patterns to move toward a system capable of achieving the energy challenge. 


\subsection{Electricity mix}

In the BAU scenario, the production of electricity gradually increases to reach $14,728 \mathrm{TJ}$ by 2030 . This growth is based on assumptions relating to the median electricity demand scenario. Electricity production from coal doubles from 2008 to 2030, indicating that without a constraint to promote energy autonomy, the most economical solution for producing electricity is based on imported coal. It is interesting to note that the share of renewable energy in the production stabilizes at around $35 \%$. This value is close to that observed in 2008 (36\%). This scenario underlines that on the one hand, the level of renewable energy in the current system is the maximum level of integration from a purely economic point of view, and on the other hand, the transition to a $100 \%$ renewable cannot be reached without an effective incentive system or regulatory constraint.

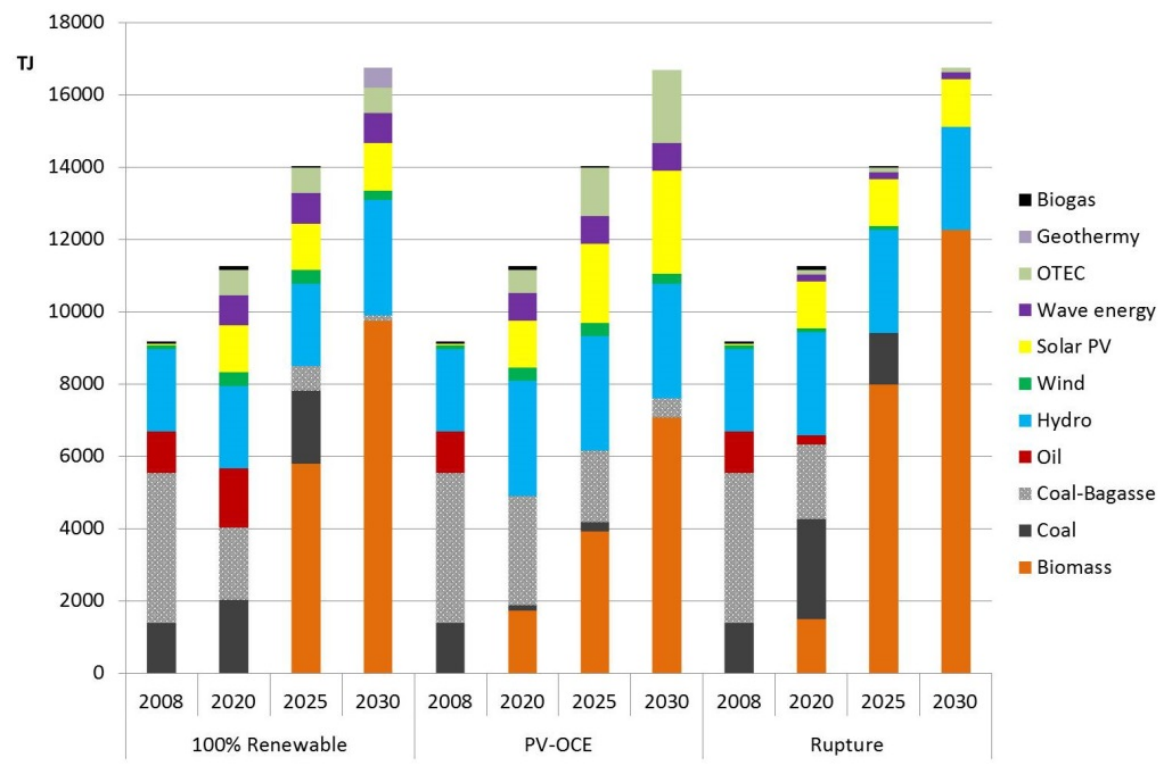

Figure 3: Electricity mix under the $100 \%$ renewable, the $P V$-OCE and the Rupture scenario (TJ)

We analyze the impact of the $100 \%$ renewable target on the electricity mix, as characterized in the 100\% Renewable scenario (figure 3). Before it is important to notice that between 2008 and 2020, electricity production increases more slowly than in a scenario without autonomy policy (BAU scenario) due to lower growth assumptions in the demand management scenario but between 2025 and 2030, the level of production catches up with the level in a $B A U$ scenario thanks to the deployment of electric vehicles. In the $100 \%$ Renewable scenario fossil fuel consumption decreases progressively. From 2020, $50 \%$ of electricity is produced from renewable energy. In 2030, electricity from biomass has advantageously replaced electricity from coal and represents slightly more than $50 \%$ of electricity generation. This can be explained by the use of new varieties of sugarcane and the opportunity to develop a sugarcane variety solely devoted to the energy production. Massive investments are made in biomass gasification plants in 2025. Geothermal energy and marine power are developed by 2030 to meet the target. 
In the PV-OCE scenario (figure 3), we can observe that production levels are the same as in the $100 \%$ renewable scenario, because we use the same demand scenario. In this scenario, photovoltaic and marine energy have been greatly encouraged. Therefore, in 2030, these two energies represent about $30 \%$ of electricity production. Hydroelectricity increases slightly between 2008 and 2020 and then remains constant over the study period, as in the other scenarios. Bioenergy is developed by 2020 due to, on the one hand, the availability of energy-dedicated sugarcane, with higher efficiency, and on the other hand, significant investments in bioplants. However, the development of biomass intervenes earlier, although to a lesser extent than in the $100 \%$ Renewable scenario. As regards wind power, production decreases over the time horizon, representing only $1.6 \%$ of the electricity mix in 2030 . Turbines are not replaced because they became less competitive compared to other investments. In this scenario, geothermal energy is not developed.

In the Rupture scenario (figure 3), there is significant development of electricity generated from biomass. Sugarcane production is being phased out in favor of energy cane. Electricity generation from bagasse rises to $12,000 \mathrm{TJ}$ in 2030 and represents more than $70 \%$ of electricity production. In addition, the geothermal option is not developed, although the activity installation in the protected natural zone is possible in this scenario. In this scenario, wind turbines are not replaced and are phased out by 2030.

\subsection{Intermittence management}

In $P V$-OCE-Int (figure 4), the share of intermittent energy sources in the power mix is limited to $30 \%$. Compared to the $P V$-OCE scenario, electricity production from solar decreases from $17 \%$ in 2030 to $14 \%$ in $P V$-OCE-Int. This intermittent production decrease is compensated by a slight increase in biomass, which represents 55\% of the power generation in comparison with 52\% in PV-OCE in 2030. However, bioplants are not developed before 2025 in PV-OCE-Int, against 2020 in PV-OCE. Wave energy is not significantly impacted by this measure. Also, fossil fuels remain a source of power generation later on and to a greater extent in $P V$-OCE-Int than in $P V$-OCE. More precisely, electricity is no longer produced by oil by 2020 in $P V$-OCE and represents $1.74 \%$ of the power mix in 2015, but $12.85 \%$ of electricity production in 2020 in $P V$-OCE-Int, before being abandoned as a resource. Twice as much coal is used in $P V$-OCE-Int than in PV-OCE in 2020 and 2025, although it only represents a small proportion of the mix.

In the $100 \%$ Ren-Int scenario (figure 4) we also consider this operating rule and also expect a lower deployment of solar panels. Compared to PV-OCE, the photovoltaic share decreases from $17 \%$ to $7 \%$ in the $100 \%$ Ren-Int scenario, but it reaches $8 \%$ in the $100 \%$ Ren scenario. Unlike the $100 \%$ Ren scenario, geothermal energy is not developed in 100\% Ren-Int. However, ocean thermal energy (OTEC) progresses faster in 100\% Ren-Int than in the 100\% Ren scenario, OTEC representing respectively $17 \%$ and $4 \%$ in 2030. Conversely, biomass progresses less, representing 47\% of power generation in 2030 in the $100 \%$ Ren-Int scenario against 58\% in the 100\% Ren scenario. Electricity from biomass represents almost $60 \%$ of the mix and the share of geothermal energy greatly increases. 


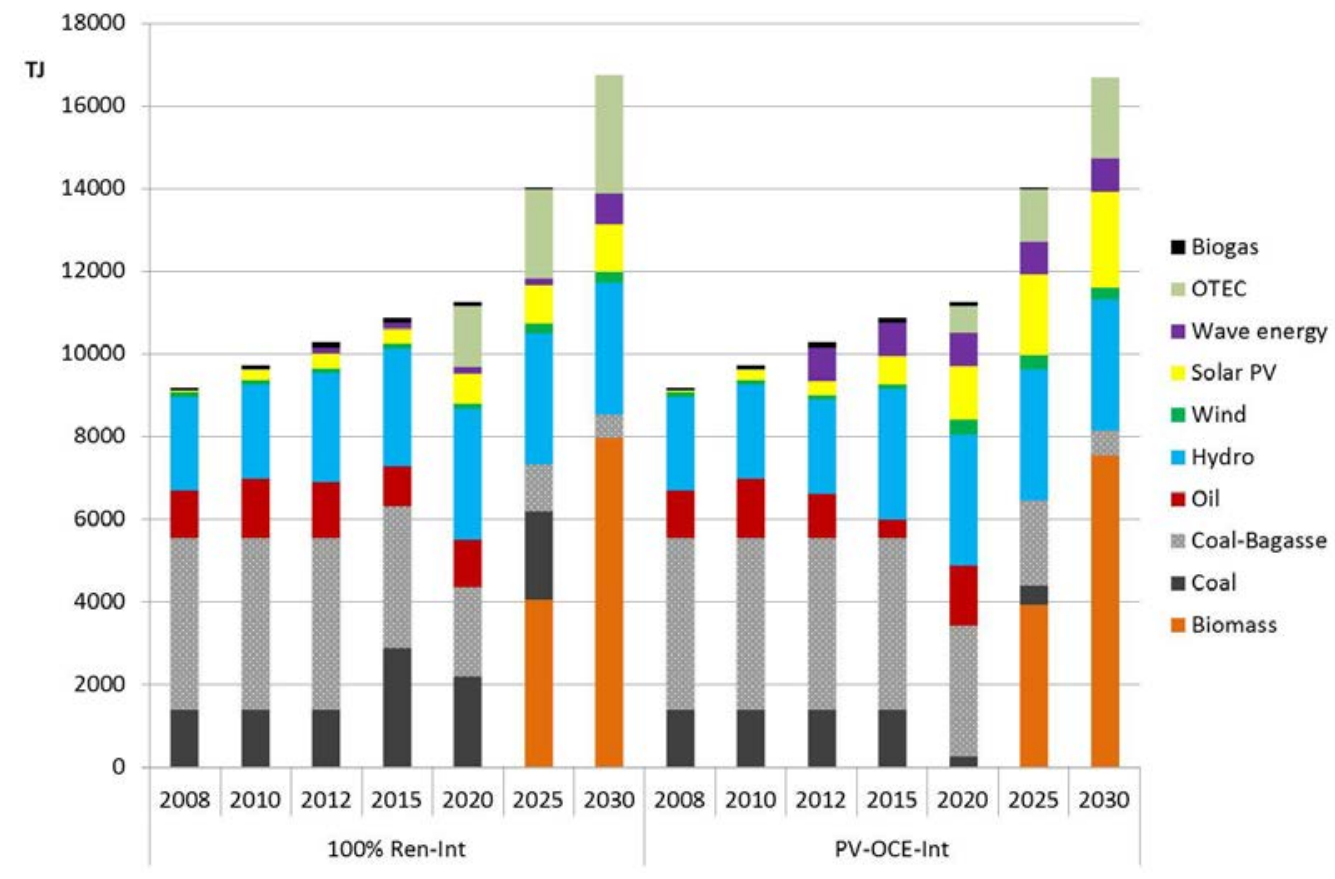

Figure 4: Electricity mix under PV-OCE-Int and 100\% Ren-Int (TJ)

\subsection{Economic impact}

The objective function of the linear optimization model TIMES-Reunion is to minimize the total discounted cost of the energy system (comprising fuel, investments, fixed and variable operation and maintenance costs, etc.) on the time horizon, given the assumed demand and technico-economic, political or environmental constraints. The decarbonized transition of the power system incurs higher total discounted system costs due to the additional costs induced by the different specific policies to promote certain renewables; some pathways toward the electricity autonomy appear more costly than others. Compare to the $B A U$, the increase of the total discounted cost of the Reunionese energy system under the $100 \%$ renewable scenario is $15 \%, 12 \%$ under the $100 \%$ Ren-Int scenario, $24 \%$ under the PV-OCE scenario, 27\% under the PV-OCE-Int scenario and $8 \%$ under the Rupture scenario.

The PV-OCE scenarios with or without the intermittence regulation rule constitute the renewable pathways involving the highest additional cost, i.e. an increase of $24 \%$ and $27 \%$ respectively for $P V-O C E$ and $P V$-OCE-Int. These scenarios are characterized by specific support for solar and marine energies and more expensive technologies.

The scenario with the least additional cost is the Rupture scenario, with only an $8 \%$ increase in the total discounted cost of the energy system. In this renewable energy pathway, the focus is on biomass and geothermal energy. In this scenario, the influence of policy is particularly strong because, on the one hand, geothermal energy exploitation is allowed in natural protected areas, even though this resource is not ultimately exploited. On the other hand, and in particular, energy cane development is promoted, to the detriment of traditional sugarcane crops. This resource and its exploitation are less expensive than sugarcane with high yields; however, the decline of the sugar industry to fully dedicate sugarcane fields to 
energy purposes is a strong policy orientation that will lead to drastic modification in Reunion Island's development, both culturally and economically.

\section{Concluding discussion}

During the 1980s, Reunion Island's entire electricity supply came from renewable hydropower. As the population grew and quality of life improved, coal and oil were introduced to help meet increasing demand. High dependence on fossil fuels for power involves security, economic and environmental problems that Reunion Island has decided to overcome by committing to sustainable growth. This involves achieving energy autonomy by 2030 and integrating zero carbon practices into multiples sectors. The priority is to reach a $100 \%$ renewable mix for power. In this challenging transition to renewable energy, Reunion Island is a source of opportunities in terms of energy development with significant solar, marine, geothermal and hydroelectric resources. This study has evaluated the changes that Reunion Island can expect in the power sector to meet its target depending on different types of support for these renewable sources of electricity. This study of the Reunion Island case is especially interesting insofar as other small island nations also face the threat of climate change and energy dependence and have the potential to lead a renewable energy revolution. "Best of all, these islands can serve as examples for the rest of the world to show how the idea of a future powered completely by renewable energy is not merely conceptual, but indeed a very realistic option with applications very much in the present" [4]. In this context, Reunion Island constitutes an interesting and effective testing ground [8][14][23] and, beyond that, can foster ambitions to be a green revolution model.

In the business as usual scenario, Reunionese electricity production doubles from 2008 to 2030, in particular based on the development of coal and the share of renewables stabilizes at around 35\% by 2030 . Despite the tremendous potential of renewables on the island, transition to $100 \%$ renewable energy requires support in the form of specific policy or constraints. Without political or economic support, the share of renewable energy remains at the 2008 level over the time horizon, suggesting that this level corresponds here to the economic maximum of renewable integration.

In this study, to discuss different pathways for energy autonomy and clean technology integration, we analyzed the impact on the electricity mix of changes in the level of renewable potentials. An interesting result is the more rapid transition with strong energy policies, i.e. the PV-OCE and Rupture scenarios. We can therefore conclude that these energy policies not only direct the choice of resources but also accelerate the renewable transition. We also focus on the level of development of solar and wave/ocean energies. These energies are not the most cost effective option, but wind power tends to disappear in the face of greater support for these energies. This result is interesting if we consider that wind is often characterized as the most common and promising renewable energy resource [3][7]. In 2000, Jensen [24] found although based on incomplete statistics - that more than $50 \%$ of islands had achieved wind power generation. However, the use of wind power differs depending on the island, and the specific cyclonic compatible wind turbine technology lead to significant investment extra-costs that limit the development of this option.

Some major technological challenges arise, particularly concerning the reliability of the electricity supply and the ability of the system to withstand sudden disturbances caused by the intermittency of certain sources of electricity. More precisely, intermittent energies can fail to guarantee the continuity and reliability of the power supply, thus disrupting the balance between energy supply and demand. Moreover, 
with respect to the wide-scale development of intermittent renewables, the scenarios investigated integrating a 30\% limitation on intermittent energy highlight that this network regulation rule works to the benefit of biomass and more to the detriment of solar than wave energy. Beyond the question of production, and especially in the case of a non-interconnected island, the issue of energy storage is crucial as a means to cope with the stochastic power production of intermittent energies [3][7]. In the future, stakeholders, i.e. industrials, researchers and public authorities, should focus on security and innovation in this area [13]. Moreover since 2009, EDF is experimenting the largest battery in Europe, a sodium-sulfur battery (Na-S) that offers high-tech storage. The sodium-sulfur battery Nas, with a capacity of 1 MW was installed in St. Andrew, a city in the northeast of Reunion Island. This experiment will enable to smooth the load curve and slightly relax the 30\% network rule [26].

The development of biomass on Reunion Island is economically more viable. By 2030 in the transition scenarios, electricity from biomass has advantageously replaced electricity from coal and represents slightly more than $50 \%$ of electricity generation. This can be explained by the use of new varieties of sugarcane and the opportunity to develop a cane variety dedicated to energy production. However, the integration of this source of biomass and the exploitation of $100 \%$ energy-sugarcane in the case of the Rupture scenario, raise questions in terms of Reunion Island's local economic development around sugarcane, sugar and rum, and the conservation of cultural aspects. For this reason, this pathway requires a particularly strong political position, such as authorizing the exploitation of geothermal energy in a protected natural area. This type of development involves the least additional cost to transit toward a decarbonized and autonomous pathway, but has significant cultural and social consequences on Reunion Island development.

\section{Acknowledgements}

This research was supported by the Chair Modeling for sustainable development, driven by MINES ParisTech, Ecole des Ponts ParisTech, and AgroParisTech, supported by ADEME, EDF, GRTgaz, SCHNEIDER ELECTRIC and the French Ministry of Ecology, Sustainable Development and Energy.

The authors thank Mathilde Drouineau, PhD from the Centre for Applied Mathematics of MINES ParisTech, for his work on the TIMES-Reunion model and her help on the understanding of its features.

\section{References}

[1] INSEE (2012), Estimations de population 2012 et 2013, projection de population 2010 à horizon 2040 (scénario central), Institut national de la statistique et des études économiques, [Last visited: 2 September, 2016], http://www.insee.fr/fr/themes/document.asp?reg_id=24\&ref_id=20826

[2] OER (2016) Bilan énergétique de lîle de La Réunion 2015, Observatoire Energie Réunion, [Last visited: 6 September, 2016], http://energies-reunion.com/wp-content/uploads/2016/07/BER-Technique2015-TOTAL-BD.pdf

[3] Mendoza-Vizcaino J., Sumper A., Sudria-Andreu A., Ramirez J.M., (2016), Renewable technologies for generations systems in islands and their application to Cozumel Island, Mexico, Renewable and Sustainable Energy Reviews, 64 (348-361). http://dx.doi.org/10.1016/j.rser.2016.06.014 
[4] Gilchrist R. (2014), How island nations can lead the renewable energy revolution, Blue and Green Tomorrow, [Last visited: 2 September, 2016], http://blueandgreentomorrow.com/features/how-islandnations-can-lead-the-renewable-energy-revolution/

[5] Duić N., Krajačić G., da Graça Carvalho M., (2008), RenewIslands methodology for sustainable energy and resource planning for islands, Renewable Sustainable Energy Review, Volume 12, Issue 4, pp.1032-62. http://dx.doi.org/10.1016/j.rser.2006.10.015

[6] Shirley R., Kammen D., (2013), Renewable energy sector development in the Caribbean: current trends and lessons from history, Energy Policy, 3, p.244-252. http://dx.doi.org/10.1016/j.enpol.2013.01.049

[7] Kuang Y., Zhang Y., Zhou B., Li C., Cao Y., Li L., Zeng L., (2016), A review of renewable energy utilization in islands, Renewable and Sustainable Energy Reviews, 59 (504-513). http://dx.doi.org/10.1016/j.rser.2016.01.014

[8] Praene J-P., David M., Sinama F., Morau D.and Marc O., (2012). Renewable energy: Progressing towards a net zero energy island, the case Reunion Island, Renewable and Sustainable Energy Reviews, 16 (426-442). http://dx.doi.org/10.1016/j.rser.2011.08.007

[9] DESA, (2010), Trends in sustainable development: Small Island Developing States (SIDS), Department of economic and social affairs.[Last visited: 5 September, 2016] http://sustainabledevelopment.un.org/content/documents/313Trends_in_Sustainable_Development_SIDS. pdf

[10] Weisser D., (2004), On the economics of electricity consumption in small island developing states: a role for renewable energy technologies, Energy Policy, 32 (1), pp.127-40. http://dx.doi.org/10.1016/S0301-4215(03)00047-8

[11] ARER (2009), PETREL - Île de la Réunion : Plan Economique de Transition et de Relance via des Energies 100\% Locales à l'Île de la Réunion. Prospective et Mix énergétique de la Réunion aux horizons 2020-2030. Contribution de l'ARER au programme STARTER de la région Réunion via la demande d'intervention de la région datée du 12 mars 2009 (référence 200904913 DEC/JD/CV) et aux travaux de Mix Energétique 2009 inscrits dans le programme Général de l’ARER. 9 juillet 2009

[12] Marín C., Alves L.M., Zervos A., (2005), 100\% RES - A challenge for island sustainable development. Instituto Superior Techico, [Last visited: 5 September, 2016], https://issuu.com/pubcipriano/docs/island100res/19

[13] Robert D., (2013), Action Plan, Territorial Growth Pact La Reunion, Pact 2014-2020, 29p. [Last visited: 2 September, 2016], http://ec.europa.eu/regional_policy/sources/activity/outermost/doc/plan action strategique eu2020 lareu nion en.pdf

[14] CGDD (2009), Le projet Réunion 2030 - GERRI, Commissariat général au développement durable, Le point sur, n² 28, Octobre 2009. 
[15] SRCAER (2013), Schéma Régional Climat Air Énergie de La Réunion, 101 p. [Last visited: 6 September, 2016], www.regionreunion.com/fr/spip/IMG/pdf/srcae.pdf

[16] Drouineau M., (2011). Modélisation prospective et analyse spatio-temporelle: intégration de la dynamique du réseau électrique, Energie électrique, Ecole Nationale Supérieure des Mines de Paris, 2011, Français. <NNT : 2011ENMP0104>. <pastel-00731894>.

[17] Bouckaert S., (2013). Contribution des Smart Grids à la transition énergétique : évaluation dans des scénarios long terme, Ecole Nationale Supérieure des Mines de Paris, 2011, Français. <NNT : 2013ENMP0056>. <pastel-00959266>.

[18] Drouineau M., Assoumou A., Mazauric V. and Maïzi N., (2011), Increasing shares of intermittent sources in Reunion Island : Impacts on the future reliability of power supply, Renewable and Sustainable Energy Reviews, 46 (120-128), http://dx.doi.org/10.1016/j.rser.2015.02.024

[19] Loulou R., Remme U., Kanudia A., Lehtila A., Goldstein G., (2005), Documentation for the TIMES Model. Part I: TIMES concepts and theory, April 2005, 78p. [Last visited: 5 September, 2016], http://docplayer.net/254952-Documentation-for-the-times-model-part-i.html

[20] Loulou R., Remme U., Kanudia A., Lehtila A., Goldstein G., (2005), Documentation for the TIMES Model. Part II: Reference manual, April 2005, 349p. [Last visited: 5 September, 2016], www.kanors.com/TestingWeb/backup/ETFinal1/docs/TIMESDoc-Details.pdf

[21] Loulou R., Remme U., Kanudia A., Lehtila A., Goldstein G., (2005), Documentation for the TIMES Model. Part III: GAMS implementation, April 2005, 20p. [Last visited: 5 September, 2016], ieaetsap.org/docs/TIMESDoc-GAMS.pdf

[22] PPI (2009), Programmation pluriannuelle des investissements de production d'électricité. Période 2009-2020, Rapport au Parlement, 2009, 132p.

[23] EDF (2016), Transition énergétique à la Réunion : l'engagement d'EDF pour les énergies renouvelables », Dossier de presse, 02/02/2016, [Last visited : 2 September, 2016], https://www.edf.fr/sites/default/files/contrib/groupe-edf/espaces-dedies/espacemedias/dp/2016/dp_edf_20160202_reunion_vf.pdf

[24] Jensen T.L., (2000), Renewable energy on small islands, second edition, Forum for Energy and Development (FED), August, 135 p. [Last visited: 6 September, 2016], http://www.gdrc.org/oceans/Small-Islands-II.pdf

[26] Grollier B., (2010), La Réunion : EDF teste une batterie géante, Les Echos, Entreprises et Régions, 12 July, 2010, [Last visited: 2 Septembre, 2016], http://www.lesechos.fr/12/07/2010/LesEchos/20717077-ECH_la-reunion---edf-teste-une-batterie-geante.htm 